\title{
EVALUATION OF D-ALLETHRIN IN THE THERMACELL MOSQUITO REPELLENT DEVICE AGAINST THE LONE STAR TICK UNDER LABORATORY CONDITIONS
}

\author{
MUHAMMAD FAROOQ, KAI BLORE, MD ASADUZZAMAN MIAH', \\ AND RUI-DE XUE \\ ANASTASIA MOSQUITO CONTROL DISTRICT, 120 EOC DRIVE, \\ ST. AUGUSTINE, FL 32092
}

'PATUAKHALI SCIENCE AND TECHNOLOGY UNIVERSITY, BANGLADESH

\author{
SUBJECT EDITOR: SETH BRITCH
}

\begin{abstract}
D-allethrin vapor generated from a personal mosquito repellent device (Thermacell MR300) was evaluated for its effectiveness to repel the lone star tick, Amblyomma americanum (adults and nymphs) when released at tick body level in a wind tunnel and in an olfactometer. In the wind tunnel $48.5 \%$ of ticks moved upwind when only attractant lure was present, while only $30.8 \%$ moved upwind when d-allethrin repellent was present with the lure. In the olfactometer strong repellency of d-allethrin vapor to adults was observed, but the effect was reduced with nymphs. Results of this study showed that d-allethrin vapor generated by the Thermacell MR300 pad could be used to reduce movement of ticks towards a host under some conditions.
\end{abstract}

Key Words: Amblyomma americanum, attractant, olfactometer, repellent, ticks, wind tunnel

Humans are at high risk of tickborne diseases but are not adequately protected from these arthropod threats (De la Fuente and Estrada-Pena 2012, MadisonAntenucci et al. 2020). In the United States, reported tickborne disease cases more than doubled from 2004 to 2018 to an all-time high and Lyme disease accounted for more than $70 \%$ of all cases in 2017 (CDC 2020). These demonstrated patterns of increased risk of tick-borne disease to humans call for improved technologies for surveillance, pathogen detection, prevention, and control of ticks. In the absence of sufficient areawide control measures targeting ticks, arthropod repellents can prevent transmission of tick-borne diseases and remain a primary option for personal protection to reduce tick bites and tick-borne diseases in tick habitats (Carroll et. al. 2005, Piesman and Eisen 2008). However, most repellents currently being used and recommended for ticks have been developed against mosquitoes and the dramatic increase in the prevalence of tick-borne diseases compels us to evaluate repellents specifically for the prevention of tick-human contact (Bissinger and Roe 2010). In this study we evaluated a spatial repellent, $d$-allethrin, produced by a device designed to protect humans from mosquito bites for its effect on questing behavior of adult ticks and nymphs in the presence and absence of an attractant using a wind tunnel and an olfactometer in a laboratory setting at the Anastasia Mosquito Control District (AMCD), St. Augustine, Florida.

The first repellency test was conducted in a modular $52 \mathrm{~cm}$ x $52 \mathrm{~cm}$ x $156 \mathrm{~cm}$ long suction-type clear glass wind tunnel (Fig. 1) using laboratory reared male and female adult lone star ticks (Amblyomma americanum) obtained from National Tick Research and Education Resource (NTRER), Oklahoma State University, Stillwater, OK. Six 15 min replicates were conducted, three using between 20-40 males for each replicate and three using 20-40 females, to measure tick movement towards a lure only and similarly 6 replicates were conducted to measure tick movement towards a combined lure and repellent. The wind tunnel plenum 
was marked with five $30 \mathrm{~cm}$ long sections to track movement of ticks from the release point (Fig. 1). The lure consisted of two BG lure cartridges (Biogents, Regensberg, Germany) and the repellent consisted of a Thermacell mosquito repellent device (Model MR300, Thermacell Repellents Inc, Bedford, MA) containing $455 \mathrm{mg} \mathrm{d}$ allethrin in a heated paper mat (Bibbs \& Xue 2016). For each lure-only replicate, the lure was placed at the upwind treatment release point (Fig. 1) and ticks were released at the downwind tick release point (Fig. 1) and allowed free movement for $15 \mathrm{~min}$, after which the number of ticks in each section of the wind tunnel plenum was recorded. For each lure+repellent replicate, the procedure was the same except both the repellent device and the lure were placed at the upwind treatment release point before releasing and counting the number of ticks in each section after 15 min.

The second repellency test was conducted using a True Choice Olfactometer (Sigma Scientific, Micanopy, FL) to investigate the repellency of $d$-allethrin vapors produced by the Thermacell device to NTRER lone star tick adults and nymphs. Ticks were released in the acclimation chamber and their movements into the two choice chambers after $10 \mathrm{~min}$ observed with and without the presence of repellent: three replicates each with new sets of ticks were conducted with fresh air drawn through both choice chambers of the olfactometer, and three replicates each with new sets of ticks were conducted with fresh air drawn through one choice chamber and d-allethrin vapors from the Thermacell drawn through the other choice chamber. Adult ticks from repellent replicates and nymphs from all replicates were retrieved and stored in vials for $24 \mathrm{~h}$ mortality determination.

For both the wind tunnel and olfactometer tests, different numbers of ticks were used in each replicate so the numbers that had moved into each section of the wind tunnel or olfactometer were converted to percentage of the total ticks used in that particular replicate. Thus, all data are reported here as percent ticks in each section or chamber. Data from the wind tunnel test were used to determine the weighted mean distance travelled by ticks using the formula:

$$
\text { Weighted Mean Distance }=\frac{\sum_{i=1-5} \mathrm{~N}_{i} \times \mathrm{D}_{i}}{\sum_{i=1-5} \mathrm{~N}_{i}}
$$

Where $N=$ number of ticks in each section $i$, and $D=$ distance from end of tunnel to the mid-point of each section $i$, which were 15 ,

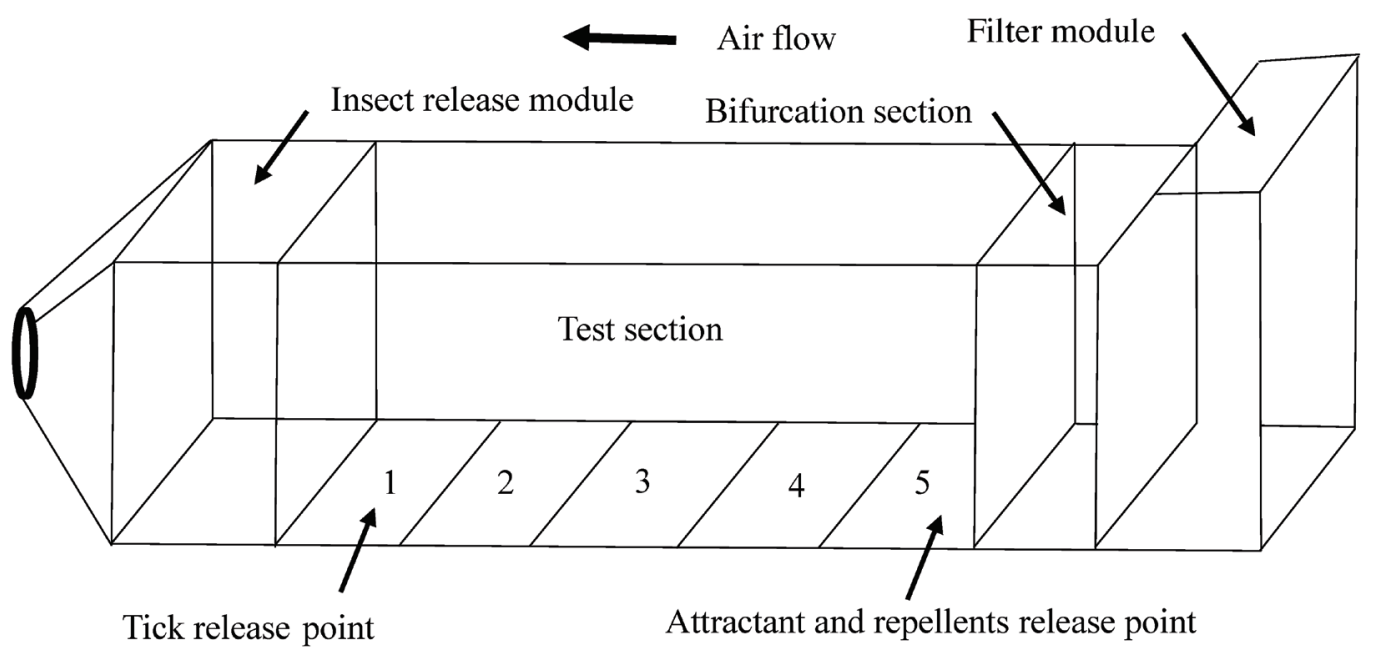

Figure 1. Diagram of wind tunnel showing tick release point and the location of the attractant and repellent release point. 
$45,75,105$, and $135 \mathrm{~cm}$ for sections $1-5$, respectively. All data were tested for normality with JMP Version 14 and found normal. Data from wind tunnel and olfactometer tests were analyzed using the analysis of variance procedure in JMP version 14 and means were evaluated using a $t$-test at $95 \%$ confidence level.

Mean tick counts in each wind tunnel section are summarized in Table 1 . The analysis indicated that regardless of the presence of the repellent, males and females behaved similarly. For both sexes, there were more ticks on the upwind treatment side when only lure was present but the trend reversed and fewer ticks were present on the upwind side when repellent was present with the lure at the upwind side. Specifically, ignoring the middle section (section 3 ), the upwind treatment release side (sections 4 and 5) had significantly higher percentage of ticks $(48.5 \%)$ than on the downwind tick release side (sections 1 and 2; 36.7\%) when only lure was in place indicating ticks were attracted to the lure. However, when the d-allethrin repellent was present with the lure on the upwind treatment release side, the tick release side had a significantly higher percentage of ticks $(57.8 \%)$ than the upwind treatment release side $(30.8 \%)$ indicating that d-allethrin vapors repelled ticks even in the presence of lure. As shown in Fig. 2, tick movement toward the lure was significantly reduced by approximately $20 \mathrm{~cm}$ in the presence of the d-allethrin repellent.

Results in Table 2 from the olfactometer test show strong repellency of d-allethrin vapors to adult ticks but less repellency to nymphs. Similarly, mortality data from the olfactometer test showed that d-allethrin vapors killed $87 \%$ of adults in $24 \mathrm{~h}$ while mortality of nymphs was $38 \%$ and $32 \%$ for no repellent and repellent treatments, respectively.

Most lone star ticks were repelled away from d-allethrin vapors in the wind tunnel test, although the vapor did not completely prevent some ticks from moving towards the repellent. Likewise, adults-but not nymphs were mostly repelled in the olfactometer test, in which we also observed high mortality in 


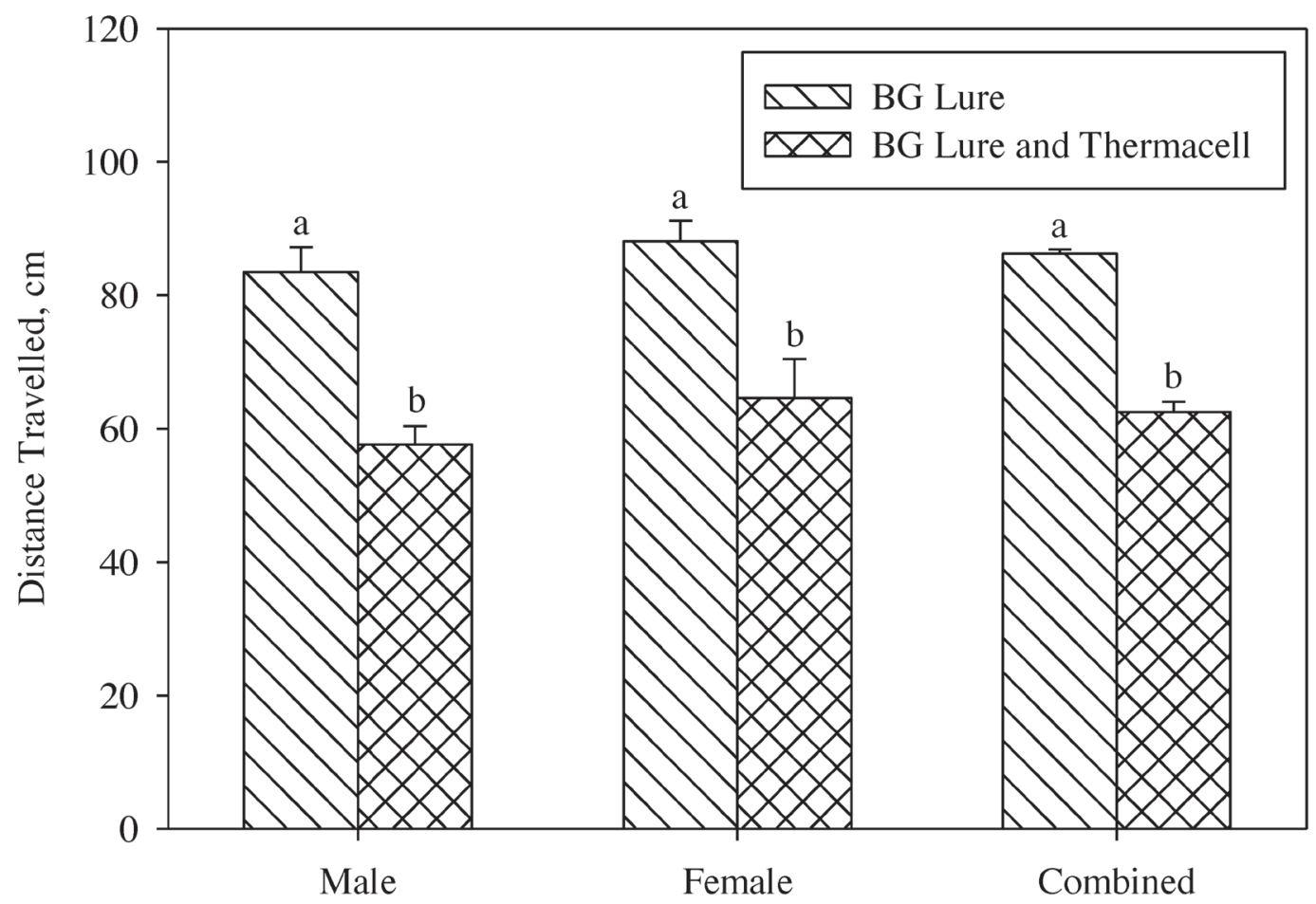

\section{Sex of Tick}

Figure 2. Comparison of weighted mean distances travelled by ticks showing significant reduction of approximately $20 \mathrm{~cm}$ in the presence of combined lure and d-allethrin.

adults in the presence of the d-allethrin vapor. The response of lone star ticks to d-allethrin in these tests were similar to results reported by Bibbs \& Xue (2016) and indicates that the d-allethrin vapor generated by the pad could be effective as a personal tick repellent and should be further evaluated in semi-field and field conditions, and against natural populations of the lone star tick and other species.

\section{ACKNOWLEDGMENT}

We thank J. Hainze for technical assistance and review of the manuscript, Thermacell, LLC, for partial funding of the project, and J. Estaver and R. Strohschein (Sigma Scientific LLC) for providing the olfactometer. This is a research report only and the mention of commercial products is to pro-

Table 2. Mean percent of ticks across the 3 chambers of the True-Choice Olfactometer.

\begin{tabular}{|c|c|c|c|c|c|}
\hline \multirow[b]{2}{*}{ Treatment } & \multirow{2}{*}{$\begin{array}{c}\text { Total } \\
\text { number ticks }\end{array}$} & \multicolumn{3}{|c|}{ Mean percent $( \pm \mathrm{SE})$ ticks in each chamber } & \multirow[b]{2}{*}{ Mortality, \% } \\
\hline & & Fresh air side & Acclimation Chamber & Repellent side & \\
\hline \multicolumn{6}{|l|}{ Adults } \\
\hline No Repellent & 15 & $26.7 \pm 13.3 \mathrm{bA}$ & $26.7 \pm 6.7 \mathrm{aA}$ & $46.7 \pm 17.6 \mathrm{aA}$ & \\
\hline Repellent & 15 & $86.7 \pm 6.7 \mathrm{aA}$ & $6.7 \pm 6.7 \mathrm{aB}$ & $6.7 \pm 6.7 \mathrm{aB}$ & 87 \\
\hline \multicolumn{6}{|l|}{ Nymphs } \\
\hline No Repellent & 16 & $20.0 \pm 11.6 \mathrm{aA}$ & $36.7 \pm 8.8 \mathrm{aA}$ & $43.3 \pm 12.0 \mathrm{aA}$ & 38 \\
\hline Repellent & 16 & $43.3 \pm 12.0 \mathrm{aA}$ & $37.8 \pm 2.2 \mathrm{aA}$ & $18.9 \pm 11.6 \mathrm{aA}$ & 32 \\
\hline
\end{tabular}

Different small letters in columns for adults and nymphs and different capital letters in rows indicate significant difference from ANOVA and $t$-tests at the $95 \%$ confidence level. 
vide specific information and does not imply endorsement by AMCD.

\section{REFERENCES CITED}

Bibbs CS, Xue RD. 2016. ThermaCell and Off! Clip-on devices tested for repellency and mortality against Amblyomma americanum (Acari: Ixodida: Amblyommidae). J Med Entomol 53:861-865.

Bissinger BW, Roe RM. 2010. Tick repellents: Past, present, and future. Pest Biochem Phys 96:63-79.

Carroll JF, Klun JA, Debboun M. 2005. Repellency of Deet and SS220 applied to skin involves olfacto- ry sensing by two species of ticks. Med Vet Entomol 19:101-106.

CDC [Centers for Disease Control and Prevention]. 2020. A National Public Health Framework for the Prevention and Control of Vector-Borne Diseases in Humans. [accessed: November 2020]. Available from https://www.cdc.gov/ncezid/dvbd/pdf/Brochure_National_Framework_VBDs-P.pdf

De la Fuente J, Estrada-Pena A. 2012. Tick and tickborne pathogens on the rise. Ticks Tick Borne Dis 3:115-116.

Madison-Antenucci S, Kramer LD, Gebhardt LL, Kauffman E. 2020. Emerging tick-borne diseases. Clin Microbiol Rev 33:e00083-18.

Piesman J, Eisen L. 2008. Prevention of tick-borne diseases. Ann Rev Entomol 53:323-334. 